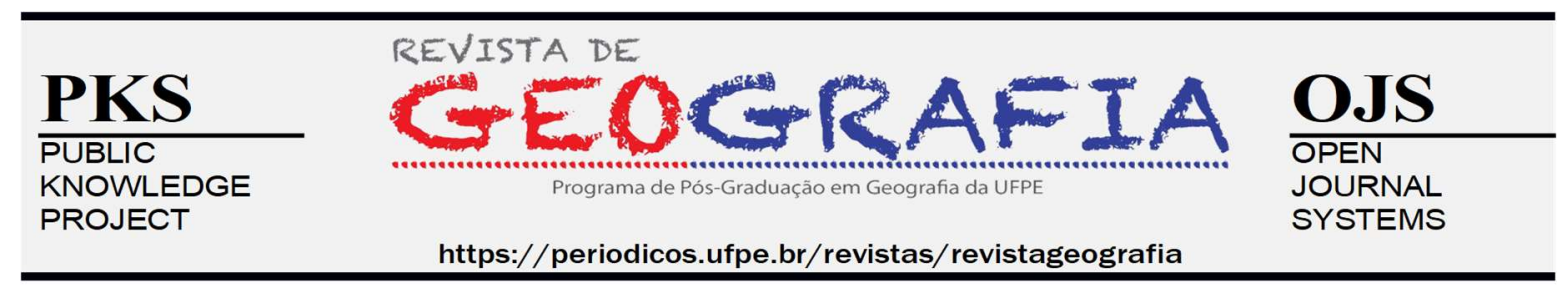

\title{
CARACTERÍSTICAS HIDROGEOLÓGICAS E HIDROGEOQUÍMICAS DO AQUÍFERO BOA VIAGEM NA PORÇÃO LESTE DO BAIRRO DA VÁRZEA-RECIFE-PE
}

\author{
Rodrigo Martins dos Santos ${ }^{1}$ \\ ${ }^{1}$ Programa de Pós-Graduação em Geociências UFPE. E-mail: msrodrigo28@gmail.com.
}

Artigo recebido em 09/09/2020 e aceito em 30/11/2020

\begin{abstract}
RESUMO
O presente artigo apresenta os resultados e conclusões, obtidos acerca das características geológicas, hidrogeológicas e hidroquímicas das águas subterrâneas do Aquífero Boa Viagem na porção leste do bairro da Várzea. O estudo constou de levantamento bibliográfico em recursos hídricos subterrâneos e dados técnicos de fichas e cadastro de poços na Cidade de Recife, com o objetivo principal de contribuir para o desenvolvimento de um modelo hidrogeológico dos recursos hídricos subterrâneos do bairro da Várzea. A análise e interpretação dos perfis construtivos e litológicos e das análises físico-químicas das águas dos poços selecionados demonstraram que o Aquífero Boa Viagem, no local estudado, é multicamadas, com diferentes composições litológicas e com águas variando de bicarbonatada sódica a mista e cloretadas sódicas.
\end{abstract}

Palavras-chave: Aquífero Boa Viagem. Bairro da Várzea. Hidroquímica. Qualidade da Água.

\section{HYDROGEOLOGICAL AND HYDROGEOCHEMICAL CHARACTERISTICS OF THE AQUIFER BOA VIAGEM IN THE EASTERN THE DISTRICT VÁRZEA-RECIFE-PE}

\section{ABSTRACT}

This article presents the results and conclusions obtained about the geological, hydrogeological and hydrochemical groundwater Boa Viagem Aquifer in eastern the district of Várzea. The study consisted of bibliographic survey in underground water resources and technical data of records and register of wells in the Recife city, with the main objective to contribute to the development of a hydrogeological model of groundwater resources of Lowland neighborhood. The analysis and interpretation of constructive and lithological profiles and physico- chemical analysis of water of the selected wells showed that the Boa Viagem Aquifer, in the study site, is multilayered, with different lithological compositions and water ranging from sodium bicarbonate mixed and sodic chlorinated.

Keywords- Boa Viagem Aquifer. Várzea district. Hydrochemistry. Water Quality.

\section{CARACTERÍSTICAS HIDROGEOLÓGICAS E HIDROGEOQUÍMICAS DEL ACUÍFERO BOA VIAGEM EN LA PARTE ESTE DEL BARRIO VÁRZEA-RECIFE-PE}

\section{RESUMEN}

En este artículo se presentan los resultados y conclusiones obtenidos sobre las características geológicas, hidrogeológicas e hidroquímicas del agua subterránea del Acuífero de Boa Viagem en la zona oriental del barrio de Várzea. El estudio consistió en un levantamiento bibliográfico de recursos hídricos subterráneos y datos 
técnicos de formularios y registro de pozos en la Ciudad de Recife, con el objetivo principal de contribuir al desarrollo de un modelo hidrogeológico de recursos hídricos subterráneos en el barrio de Várzea. El análisis e interpretación de los perfiles constructivos y litológicos y los análisis físico-químicos de las aguas de los pozos seleccionados demostraron que el Acuífero de Boa Viagem, en el sitio estudiado, es multicapa, con diferentes composiciones litológicas y con aguas que van desde bicarbonato de sodio a mezcla y cloruro de sodio.

Palabras clave: Acuífero de Boa Viagem. Bairro da Várzea. Hidroquímica. Calidad del agua.

\section{INTRODUÇÃO}

A região do Recife, capital do estado de Pernambuco, é abastecida parcialmente por cerca de 35\% de sua demanda hídrica por águas subterrâneas dos seguintes Aquíferos, segundo Costa et al (2004): Aquífero Boa Viagem, de idade holocênica (recente), Aquífero Barreiras, de idade pleistocênica, Aquífero Beberibe e do Aquífero Cabo, ambos de idade cretácea.

Com um grande crescimento populacional na década de 70, a cidade de Recife, a exemplo de outras capitais nordestinas, também significou aumento na sua demanda por água potável nas suas áreas urbanas. Porém, em razão de secas severas, como a ocorrida entre 1998 e 1999, e de frequentes racionamentos de água, o município aumentou o uso de águas subterrâneas por meio da perfuração de poços privados, localizados, principalmente, no centro da cidade e no bairro de Boa Viagem. Esse aumento na exploração dessas águas tem ocorrido de forma desordenada, pois são mais de 13 mil poços perfurados na região (HIRATA, 2018) e muitos deles são ilegais, ou seja, sem registros nos órgãos competentes. Um outro fator negativo com os poços privados é que muitos se tornam salinizados e são perdidos e abandonados. Parte do Aquífero de Boa Viagem, que é mais raso e de menor espessura, também é afetado com esses problemas.

Trabalhos envolvendo estudos hidrogeoquímicos das águas subterrâneas do município de Recife já foram realizados, porém estas pesquisas não tiveram como alvo principal a caracterização hidroquímica de suas unidades aquíferas em separado.

Portanto, o principal objetivo da pesquisa foi à caracterização geológica, bem como a hidrogeoquímica do Aquífero Boa Viagem, na porção leste do bairro da Várzea, município de Recife-PE, para fornecer subsídios ao desenvolvimento de um modelo hidrogeológico dos recursos hídricos subterrâneos. Esse Aquífero vem sendo explorado pela população, comércio e indústrias locais, em função da irregularidade do fornecimento d'água pela Companhia Pernambucana de Saneamento (COMPESA). 
A caracterização geológica contribuiu para um melhor conhecimento hidrogeológico, hidroquímico e de vulnerabilidade do Aquífero Boa Viagem. O estudo hidroquímico identificou e quantificou os principais constituintes químicos, com vistas à classificação e diferenciação entre as camadas do Aquífero Boa Viagem, definido pelo estudo geológico e hidrogeológico. As águas enriquecem em sais ao lixiviar os solos, sedimentos e rochas, ao longo de seu trajeto, principalmente, pela dissolução dos minerais. Por isso as águas do Aquífero Boa Viagem têm composição química diferenciada nas distintas camadas.

\section{METODOLOGIA DE ESTUDO}

O trabalho inicial consistiu em levantamento bibliográfico de relatórios de poços e de análises hidroquímicas das águas subterrâneas. A interpretação geológica e hidrogeológica do Aquífero Boa Viagem baseou-se nos perfis litológicos e construtivos dos poços selecionados da dissertação de Mestrado de Batista (1984) e de cópias de relatórios obtidos pessoalmente pelos autores na Agência Pernambucana de Águas e Climas (APAC).

Os dados disponibilizados pela APAC constavam de fichas de análises físico química das águas dos poços atualizados até o ano de 2013, porém na área de estudo (bairro da Várzea) devido ao critério de seleção dos dados somente houve aproveitamento das análises correspondentes ao ano de 2008.

As premissas para seleção dos poços e análises se basearam nos seguintes critérios:

- localização geográfica dos poços;

- registros dos perfis litológicos (estratigráficos) dos poços *;

- perfis construtivos dos poços (dados referentes ao topo e base dos filtros);

- análises físico - química (consideradas com erro de confiabilidade " $e$ " de até $10 \%)$.

* As descrições litológicas dos furos foram obtidas nos dados, mas as devidas interpretações foram elaboradas pelos autores e anexada na tabela 2.

Neste trabalho optou-se por digitalizar os poços e as análises selecionadas como forma de melhor visibilidade e organização dos dados. Ressaltando que não houve viabilidade econômica na pesquisa para custear análises mais recentes em laboratório, contudo o objetivo é a caracterização hidrogeoquímica dessas águas aquíferas em diferentes interfaces do substrato rochoso em profundidade e a qualidade delas. 
O critério de confiabilidade do erro $(e \%)$ das análises foi feito através de cálculos do balanço iônico, partindo do princípio de que numa análise físico - química completa, a concentração total de cátions, em miliequivalente por litro (meq/L), deve ser igual à de ânions. Esse é o método padrão utilizado para julgar a precisão de uma análise (SANTOS, 2008), segundo a expressão:

$$
\operatorname{Erro}(\%)=\left|\frac{\mathrm{r} \sum \mathrm{p}-\mathrm{r} \sum \mathrm{n}}{\mathrm{r} \sum \mathrm{n}+\mathrm{r} \sum \mathrm{p}}\right| \mathrm{x} \mid \mathrm{Onde}
$$

$r \sum p=$ concentração total de cátions em miliequivalente por litro $(\mathrm{meq} / \mathrm{L})$

$r \sum n=$ concentração total de ânions em miliequivalente por litro $(\mathrm{meq} / \mathrm{L})$

As análises selecionadas consistiram dos principais cátions e ânions respectivamente: $\left(\mathrm{Na}^{+}, \mathrm{K}^{+}, \mathrm{Ca}^{2+}\right.$ e $\left.\mathrm{Mg}^{2+}\right),\left(\mathrm{Cl}^{-}, \mathrm{NO}_{3}{ }^{-}, \mathrm{SO}_{4}{ }^{2-}, \mathrm{HCO}_{3}{ }^{-}\right.$e $\left.\mathrm{CO}_{3}{ }^{-2}\right)$, entre outros parâmetros hidroquímicos descritos no item caracterização hidroquímica. Com a ausência dos elementos, $\mathrm{HCO}_{3}{ }^{-}$(bicarbonato), $\mathrm{CO}_{3}^{-2}$ (carbonato) e $\mathrm{OH}^{-}$(hidróxido) em algumas análises, estas foram complementadas pela fórmula de Logan (1965), baseadas na alcalinidade total e no pH como segue:

a) Para o Bicarbonato:

$$
\mathrm{HCO}_{3}^{-}=\left|\frac{(\text { Alcal. } \div 50)+10^{(3-\mathrm{pH})}-10^{(p H-11)} \times 61,02}{1+\left(9,38 \times 10^{(p H-11)}\right)}\right|_{\mathrm{mg} / 1}
$$

b) Para o Carbonato:

$$
\mathrm{CO}_{3}^{-2}=\left|\left(\frac{\mathrm{HCO}_{3}^{-}}{61,02}\right) \times 9,38 \times 10^{(p H-11)} \times 30,01\right| \mathrm{mg} / 1 \text { (2) }
$$

c) Para o Hidróxido:

$$
\mathrm{OH}^{-}=\left|10^{(p H-11)} \times 17,01\right| \mathrm{mg} / \mathrm{l}(3)
$$


Para classificação dos tipos de águas subterrâneas foi elaborado um diagrama triangular de Piper com auxílio do Software Qualigraf. Para plotar no diagrama, transformouse o valor de cada íon expresso em meq/L em percentagem dos totais de ânions e de cátions, separadamente.

\section{LOCALIZAÇÃO DA ÁREA, ASPECTOS OCUPACIONAIS E CLIMÁTICOS.}

As análises das águas subterrâneas diagnosticadas foram realizadas através de três poços selecionados e situados no leste do bairro da Várzea (figura 01). O bairro tem a segunda maior em extensão territorial do Recife, com 2.264 hectares de área e uma população residente de 70.453 habitantes (IBGE, 2010). A área encontra-se inserida na zona fisiográfica do Litoral-Mata Atlântica no Estado de Pernambuco, trata-se de uma região tropical litorânea, quente e úmida com estiagem pouco pronunciada. Segundo a classificação de Koppen (1948) o clima é do tipo Ams', quente e úmido, com taxa de precipitação pluviométrica anual abundante com média de 2.457,90 $\mathrm{mm}$.

Figura 01 - Mapa de localização da área e dos poços estudados

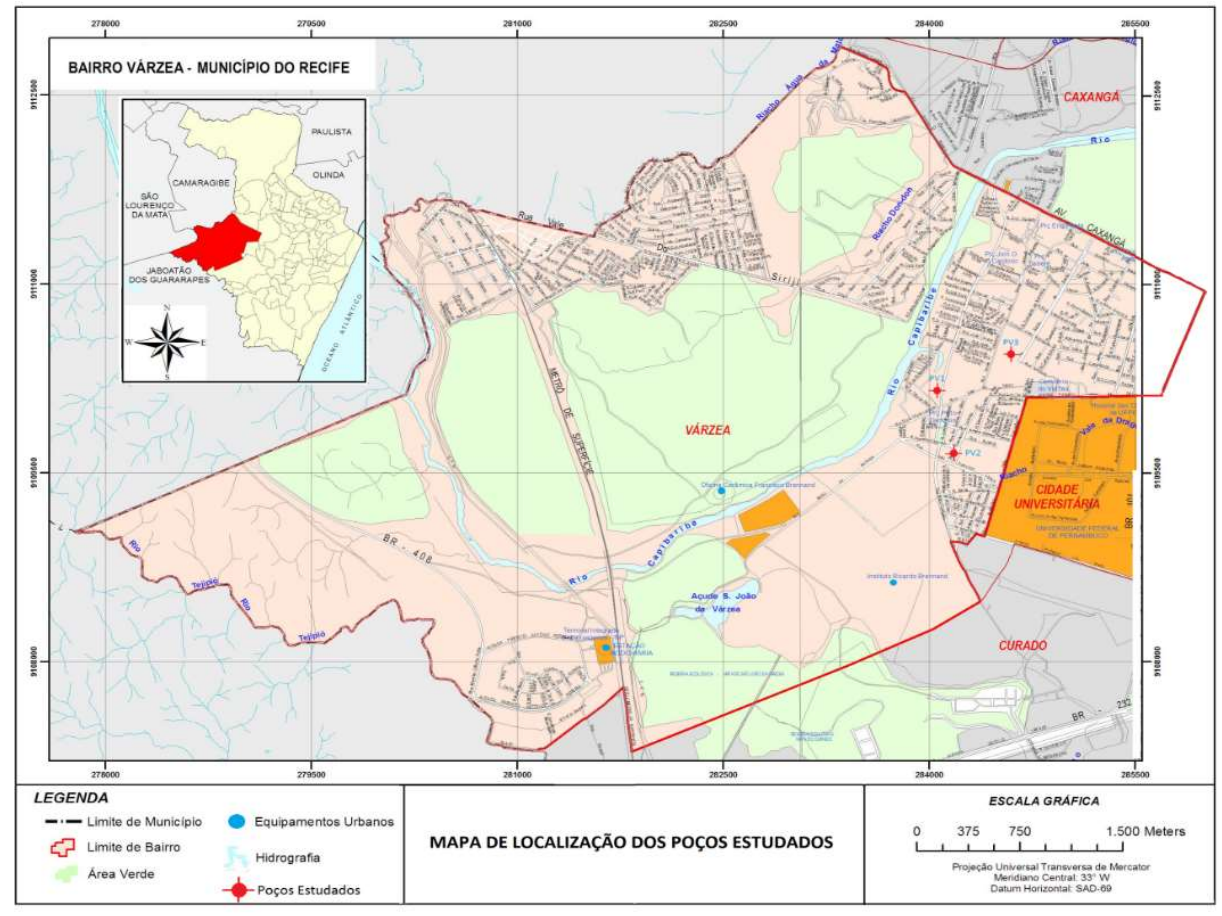

Fonte: Atlas do desenvolvimento humano na Região Metropolitana do Recife (2011), modificado. 


\section{CARACTERIZAÇÃO HIDROGEOLÓGICA}

O bairro da Várzea encontra-se inserido morfologicamente numa planície de formação geológica flúvio-marinha, situada no extremo sudoeste da Bacia Sedimentar da Paraíba.

A Bacia Sedimentar da Paraíba localiza-se onde provavelmente foi o último elo entre a África e o Brasil (RAND \& MABESOONE, 1982), o que a torna possuidora de características estratigráficas e estruturais, peculiares em relação às bacias circunvizinhas, além de possuir uma formação e um preenchimento sedimentar tardio (BARBOSA, 2004). Nela encontra-se o principal reservatório de água subterrânea da Região Metropolitana do Recife, o Aquífero Beberibe. O mesmo, não está presente na área estudada, ocorrendo apenas o Aquífero Boa Viagem.

Nesse sentido, o Aquífero Boa Viagem é caracterizado por um conjunto de depósitos recentes do Quaternário, incluindo aluviões, eluviões, coluviões, terraços fluviais, terraços marinhos, areias de praia e dunas antigas, todos localizados na região deltaica do conjunto dos rios Capibaribe, Beberibe e Tejipió, formando-se assim a atual planície do Recife. Por se tratar de um depósito poligênico, originados por sucessivas variações da linha de costa devidas as oscilações da superfície do nível do mar durante o Holoceno e Pleistoceno, sua constituição granulométrica é intensamente variada, desde a fração argilosa até a fração de areia grosseira, com níveis de cascalho, sobretudo, nos terraços fluviais. Esta sequência de sedimentos recobre o embasamento cristalino na área pesquisada (bairro da Várzea).

Os poços utilizados para caracterização hidrogeológica e hidroquímica do Aquífero Boa viagem, localmente no bairro da Várzea, tiveram como critério de seleção, possuir informações dos perfís construtivos, perfis litológicos e dados físico-químicos das águas subterrâneas do Aquífero captado.

Os três poços selecionados estão localizados na borda sudoeste da Bacia Paraíba e foram denominados neste trabalho, Pv1, Pv2 e Pv3, os quais têm suas profundidades variando de 19,20 a 64,00 metros (m) conforme ilustrados nas figuras 02, 03 e 04. 


\section{CARACTERIZAÇÃO HIDROQUÍMICA}

O presente trabalho abordará os principais parâmetros como $\mathrm{pH}$, Condutividade elétrica, sólidos totais dissolvidos e a dureza da água, assim também, os principais íons para caracterização hidroquímica da água nos três poços.

O Potencial hidrogeniônico $(\mathrm{pH})$ representa a concentração de íons hidrogênio $\mathrm{H}^{+}$ (em escala anti-logarítmica), dando uma indicação sobre a condição de acidez $(\mathrm{pH}<7)$, neutralidade $(\mathrm{pH}=7)$ e alcalinidade da água $(\mathrm{pH}>7)$.

A condutividade elétrica (CE), que está diretamente ligada ao teor de sais dissolvidos sob a forma de íons. Os sólidos totais dissolvidos (STD) representam a dissolução do material dissolvido na água. Na maioria das águas subterrâneas naturais, a condutividade elétrica da água multiplicada por um fator, que varia entre, 0,55 e 0,75 , gera uma boa estimativa para os sólidos totais dissolvidos na água. O valor de STD nas águas doces varia de 50 a $1.500 \mathrm{mg} / \mathrm{L}$ e nos mares, em torno de $35.000 \mathrm{mg} / \mathrm{L}$, podendo atingir $300.000 \mathrm{mg} / \mathrm{L}$ em salmouras (SANTOS, 2008).

A dureza (Tabela 1) é a capacidade de a água neutralizar o sabão pelo efeito do cálcio, magnésio ou outros elementos como $\mathrm{Fe}, \mathrm{Mn}, \mathrm{Cu}$ e $\mathrm{Ba}$.

Tabela 1- Tabela com a classificação das águas segundo a dureza em mg/L de $\mathrm{CaCO}_{3}$

\begin{tabular}{|l|l|}
\hline Tipo & Teor de $\mathrm{CaCO}_{3}(\mathbf{m g} / \mathbf{L})$ \\
\hline Branda & $<50$ \\
\hline Pouco Dura & $50-100$ \\
\hline Dura & $100-200$ \\
\hline Muito Dura & $>200$ \\
\hline
\end{tabular}

Fonte: Adaptado de Custodio \& Llamas (1983)

\section{CLASSIFICAÇÃO HIDROQUÍMICA}

As águas subterrâneas estudadas nos três poços foram denominadas segundo à classificação iônica a qual serve para identificar a água com relação aos íons dominantes, tanto de ânions como de cátions. 
Os íons são dominantes quando sua concentração ultrapassa $50 \%$ da soma em miliequivalentes de todos os íons monovalentes. Se os íons têm valores menores ou iguais a $50 \%$ da soma em miliequivalentes de todos os íons monovalentes, então a água é denominada de acordo com os ânions e cátions mais abundantes.

Para classificar a água subterrânea quanto íon dominante foi elaborado um diagrama de Piper (figura 5). O balanço iônico, ou seja, o erro percentual de confiabilidade dos dados físico-químico foi admitido neste artigo de 10\% como mencionado anteriormente.

A diferença de solubilidade das espécies iônicas é responsável pela evolução química das águas com a profundidade. À medida que se infiltram nas formações geológicas as águas tendem a apresentar a seguinte evolução: bicarbonatadas $\Rightarrow$ sulfatadas $\Rightarrow$ cloretadas.

\section{RESULTADOS E DISCUSSÕES}

\section{Perfis litológicos}

O Pv1 é um poço freático que explota águas de uma camada aluvionar e de uma camada aluvionar (cristalino alterado). O Pv2 a água é captada na porção superior no intervalo de 6 a 10 metros numa camada aquífera aluvionar freática e o Pv3 retira água do Aquífero aluvionar confinado não drenante representado pela porção do cristalino alterado (regolito).

Figura 02 - Dados Construtivo e Litológicos do Poço Pv1

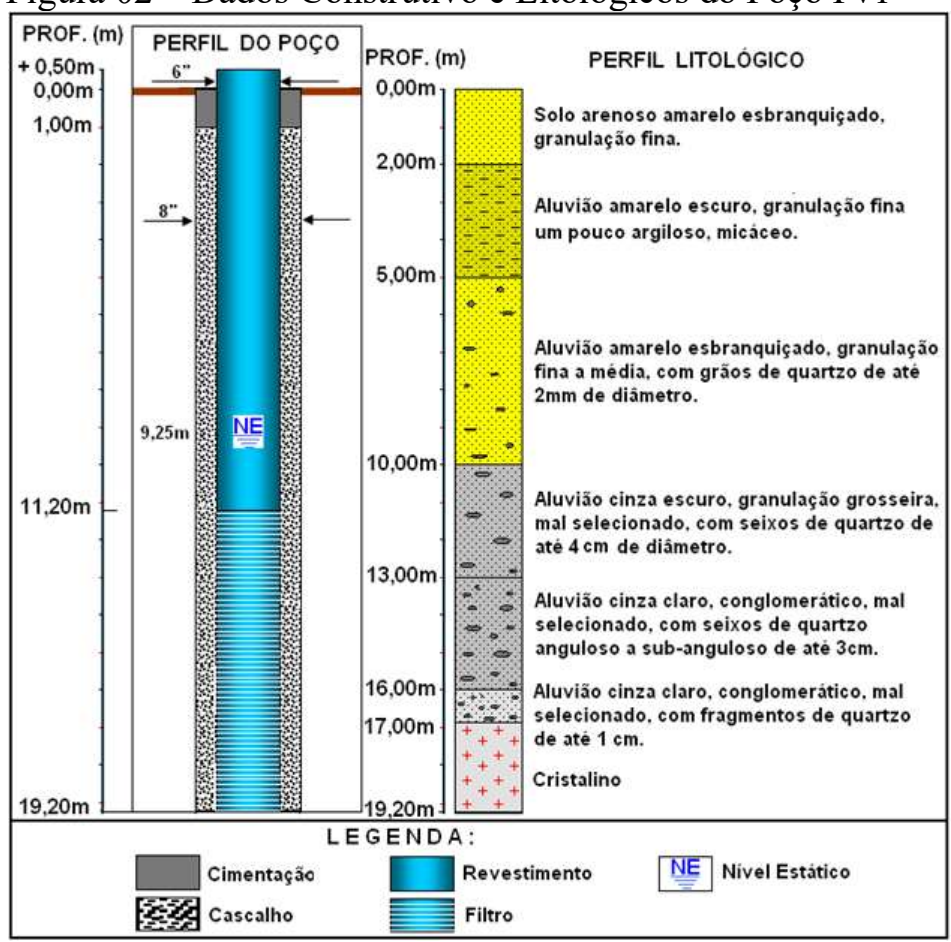

Fonte: Elaborado pelos autores (2016). 
Figura 03 - Dados Construtivo e Litológicos do Poço Pv2

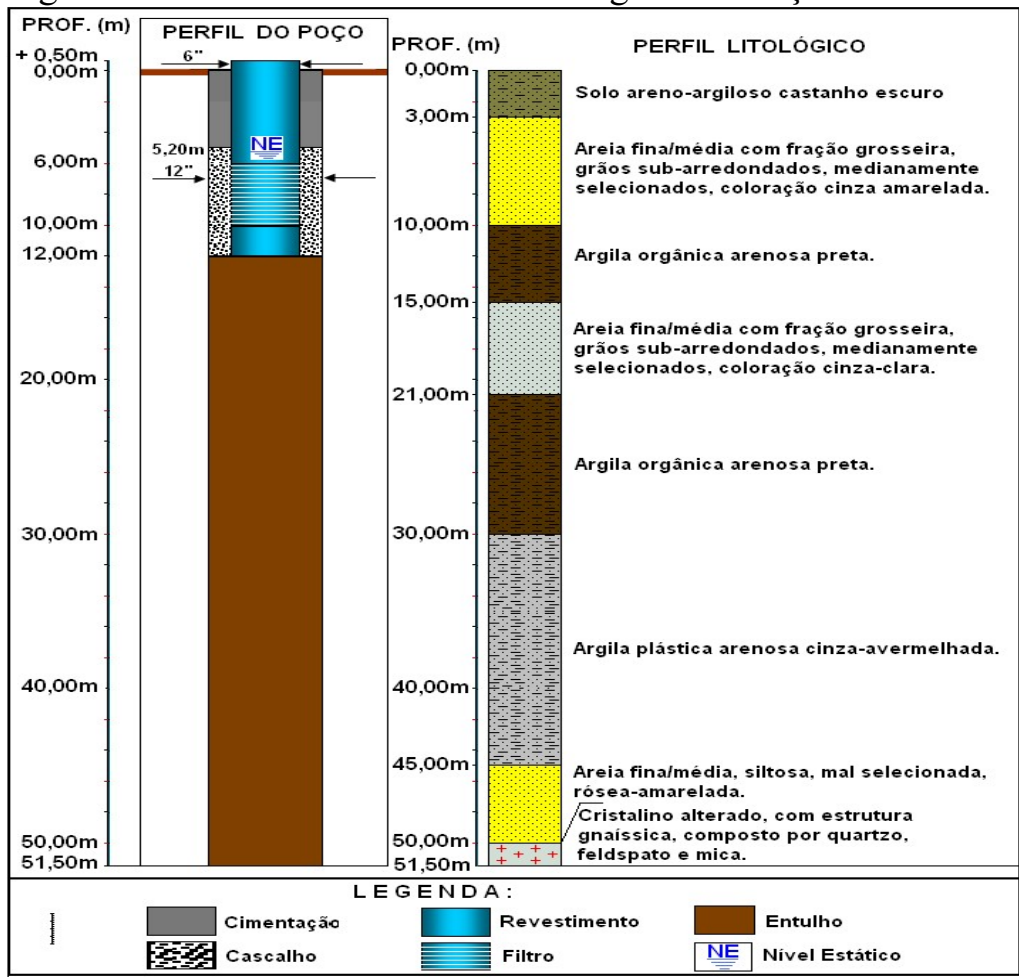

Fonte: Batista (1984), modificado.

Figura 04 - Dados Construtivo e Litológicos do Poço Pv3

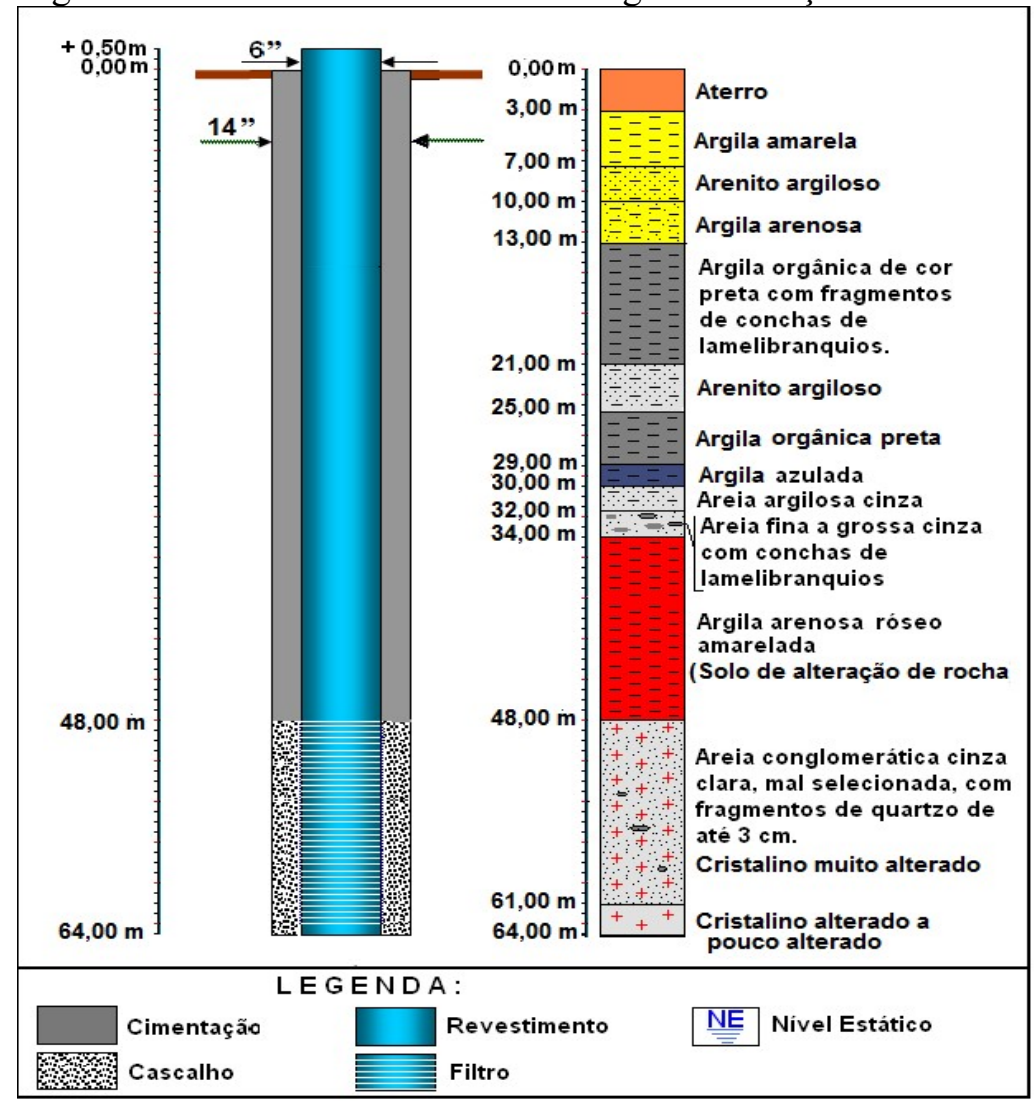

Fonte: Elaborado pelos autores (2016). 
De acordo com os perfís litológicos dos poços selecionados, a área é caracterizada por uma sequência de sedimentos recentes, os quais predominam os depósitos de origem eluvionar, capeados por sedimentos lagunar estuarino que ocupam as regiões baixas, próximas do vale do rio Capibaribe e sedimentos fluviais. Os sedimentos de origem lagunar estuarina estão relacionados à última transgressão denominada por Bittencourt et al. (1979), e são constituídos sobretudo por areias finas a grossas com porções siltico a argilosas e intercalações de argilas rica em matéria orgânica (paleomangues).

Tabela 2 - Tabela com as descrições e interpretações litológica dos furos

\begin{tabular}{|c|c|c|c|c|}
\hline Poco & & Descrição litológica dos furos & \multicolumn{2}{|c|}{ Interpretação litológica dos furos } \\
\hline \multirow{7}{*}{ Pv1 } & $0-2$ & $\begin{array}{l}\text { Solo arenoso amarelo esbranquiçado, } \\
\text { granulação fina. }\end{array}$ & \multirow{3}{*}{$\begin{array}{l}\text { Areias granulação fina a média } \\
\text { de coloração amarela clara a } \\
\text { escura, com argila e mica. }\end{array}$} & \multirow{3}{*}{$\begin{array}{l}\text { Sedimento } \\
\text { aluvionar }\end{array}$} \\
\hline & $2-5$ & $\begin{array}{l}\text { Aluvião amarelo -escuro, granulação } \\
\text { fina, um pouco argiloso, micáceo. }\end{array}$ & & \\
\hline & $5-10$ & $\begin{array}{l}\text { Aluvião amarelo esbranquiçado, } \\
\text { granulação fina a média, com grãos } \\
\text { de quartzo até } 2 \mathrm{~mm} \text {. }\end{array}$ & & \\
\hline & $10-13$ & $\begin{array}{l}\text { Aluvião cinza escuro, granulação } \\
\text { grosseira, mal selecionado, com } \\
\text { seixos de quartzo de até } 4 \mathrm{~cm} \text { de } \\
\text { diâmetro. }\end{array}$ & \multirow{3}{*}{$\begin{array}{l}\text { Areias granulação grossa de } \\
\text { coloração cinza claro a escuro } \\
\text { com grânulos e seixos de } \\
\text { quartzo angulosos a } \\
\text { subangulosos de até } 3 \mathrm{~cm} \text {. }\end{array}$} & \multirow{3}{*}{$\begin{array}{l}\text { Sedimento } \\
\text { eluvionar }\end{array}$} \\
\hline & $13-16$ & $\begin{array}{l}\text { Aluvião cinza claro, conglomerático, } \\
\text { mal selecionado, com seixos de } \\
\text { quartzo angulosos a subangulosos de } \\
\text { até } 3 \mathrm{~cm} \text {. }\end{array}$ & & \\
\hline & $16-17$ & $\begin{array}{l}\text { Aluvião cinza claro, conglomerático, } \\
\text { mal selecionado, com fragmentos de } \\
\text { quartzo de até } 1 \mathrm{~cm} \text {. }\end{array}$ & & \\
\hline & $17-19,2$ & Embasamento & \multicolumn{2}{|c|}{ Embasamento cristalino não decomposto } \\
\hline Pv2 & $0-3$ & Solo areno-argiloso castanho escuro & Solo orgânico & Sedimento aluvionar \\
\hline
\end{tabular}




\begin{tabular}{|c|c|c|c|c|}
\hline & $3-10$ & $\begin{array}{l}\text { Areia fina/média com fração } \\
\text { grosseira, grãos sub-arredondados, } \\
\text { mediatamente selecionados, } \\
\text { coloração cinza amarelada. }\end{array}$ & $\begin{array}{l}\text { Areias de granulação finas a } \\
\text { grossa de coloração cinza } \\
\text { amarelada com grãos sub- } \\
\text { arredondados, mediatamente } \\
\text { selecionados. }\end{array}$ & \\
\hline & $10-15$ & Argila orgânica arenosa preta. & $\begin{array}{l}\text { Argila orgânica arenosa } \\
\text { preta. (Paleomangue) }\end{array}$ & \multirow{3}{*}{$\begin{array}{l}\text { Terraço } \\
\text { flúvio-marinho }\end{array}$} \\
\hline & $15-21$ & $\begin{array}{l}\text { Areia fina/média com fração } \\
\text { grosseira, grãos sub-arredondados, } \\
\text { mediatamente selecionados, } \\
\text { coloração cinza claro. }\end{array}$ & $\begin{array}{l}\text { Areias de granulação finas a } \\
\text { grossa de coloração cinza } \\
\text { clara com grãos sub- } \\
\text { arredondados, mediatamente } \\
\text { selecionados. }\end{array}$ & \\
\hline & $21-30$ & Argila orgânica arenosa preta & $\begin{array}{l}\text { Argila orgânica arenosa } \\
\text { preta. (Paleomangue) }\end{array}$ & \\
\hline & $10-45$ & Argila plástica cinza -avermelhada. & $\begin{array}{l}\text { Argila plástica de coloração } \\
\text { cinza -avermelhada }\end{array}$ & \multirow[b]{2}{*}{$\begin{array}{l}\text { Sedimento } \\
\text { eluvionar }\end{array}$} \\
\hline & $45-50$ & $\begin{array}{l}\text { Areia fina/média, siltosa, mal } \\
\text { selecionada, rósea-amarelada. }\end{array}$ & $\begin{array}{l}\text { Areia de granulação fina a } \\
\text { média, siltosa de coloração } \\
\text { rósea-amarelada, mal } \\
\text { selecionada. }\end{array}$ & \\
\hline & $50-51,5$ & $\begin{array}{l}\text { Cristalino alterado, com estrutura } \\
\text { gnáissica, composto por quartzo, } \\
\text { feldspato e mica. }\end{array}$ & \multicolumn{2}{|c|}{$\begin{array}{l}\text { Quartzo-feldspato biotita Gnaisse alterado } \\
\text { (Embasamento cristalino) }\end{array}$} \\
\hline \multirow{6}{*}{ Pv3 } & $0-3$ & Aterro & & Aterro \\
\hline & $3-7$ & Argila amarela & \multirow{3}{*}{$\begin{array}{l}\text { Argilas e areias argilosas de } \\
\text { coloração amarelada }\end{array}$} & \multirow{3}{*}{$\begin{array}{l}\text { Sedimento. } \\
\text { Aluvionar }\end{array}$} \\
\hline & $7-10$ & Arenito argiloso & & \\
\hline & $10-13$ & Argila arenosa & & \\
\hline & $13-21$ & $\begin{array}{l}\text { Argila orgânica de cor preta com } \\
\text { fragmentos de concha de } \\
\text { lamelibrânquios. }\end{array}$ & $\begin{array}{l}\text { Argila orgânica de cor preta } \\
\text { com fragmentos de concha } \\
\text { de lamelibrânquios (paleo- } \\
\text { mangue) }\end{array}$ & Terraço \\
\hline & $21-25$ & Areia argilosa & $\begin{array}{l}\text { Areia argilosa (paleo- } \\
\text { mangue) }\end{array}$ & fluvio-marinho \\
\hline
\end{tabular}




\begin{tabular}{|c|c|c|c|}
\hline $25-29$ & Argila orgânica preta & $\begin{array}{l}\text { Argila orgânica preta (paleo- } \\
\text { mangue) }\end{array}$ & \\
\hline $29-30$ & Argila azulada & $\begin{array}{l}\text { Argila azulada (paleo- } \\
\text { mangue) }\end{array}$ & \\
\hline $30-32$ & Areia argilosa cinza & $\begin{array}{l}\text { Areia argilosa cinza (paleo- } \\
\text { mangue) }\end{array}$ & \\
\hline $32-34$ & $\begin{array}{l}\text { Areia fina a grossa cinza com } \\
\text { conchas de lamebranquios. }\end{array}$ & $\begin{array}{l}\text { Areia fina a grossa cinza } \\
\text { com conchas de } \\
\text { lamebranquios }\end{array}$ & \\
\hline $43-48$ & $\begin{array}{l}\text { Argila arenosa- róseo -amarelada } \\
\text { (solo de alteração de rocha) }\end{array}$ & $\begin{array}{l}\text { Argila arenosa de coloração } \\
\text { rosa-amarelada }\end{array}$ & \multirow{3}{*}{$\begin{array}{l}\text { Sedimento } \\
\text { eluvionar }\end{array}$} \\
\hline $48-61$ & $\begin{array}{l}\text { Areia conglomerática cinza- clara, } \\
\text { mal selecionada, com fragmentos de } \\
\text { quartzo de até } 3 \mathrm{~cm} \text {. Cristalino muito } \\
\text { alterado. }\end{array}$ & $\begin{array}{l}\text { Areia grossa de coloração } \\
\text { cinza clara, mal selecionada, } \\
\text { com fragmentos de quartzo } \\
\text { de até } 3 \mathrm{~cm} .\end{array}$ & \\
\hline $61-64$ & Cristalino alterado a pouco alterado & $\begin{array}{l}\text { Cristalino alterado a pouco } \\
\text { alterado }\end{array}$ & \\
\hline
\end{tabular}

Fonte: Elaborado pelo autor (2016).

\section{Parâmetros hidroquímicos}

Os dados físico-químicos das águas subterrâneas analisadas nos três poços estão inseridos nas tabelas 3 e 4 . O pH nessas águas variou de 7,4 a 10,1, indicando o predomínio de águas alcalinas. A condutividade elétrica (CE) variou nos três poços estudados de 746 a $1.200 \mu \mathrm{Mho} / \mathrm{cm}$, nesse parâmetro hidroquímico o Pv2 apresentou a maior condutividade elétrica devido ao alto teor de sais dissolvidos (STD).

Nos três poços os Sólidos Totais Dissolvidos (STD) variou de 463 a 854mg/l, correspondendo a valores de águas doces.

Em relação a dureza das águas nos três poços, as águas subterrâneas no Pv1 e Pv2 são brandas e no Pv3 como água dura, sendo está última com maior produção de consumo de sabão, dificultando o cozimento de alimentos. 
Tabela 3- Tabela com os valores de pH, Condutividade elétrica (CE), Dureza e Sólidos Totais Dissolvidos (STD).

\begin{tabular}{|c|c|c|c|c|}
\hline Poço & $\mathbf{p H}$ & $\mathbf{C E}(\boldsymbol{\mu}-\mathbf{m h o} / \mathbf{c m})$ & Dureza $\left(\mathbf{m g} / \mathbf{l} \mathbf{~ d e ~} \mathbf{C a C O}_{3}\right)$ & $\mathbf{S T D}(\mathbf{m g} / \mathbf{l})$ \\
\hline Pv1 & 7,8 & - & 21 & 463 \\
\hline Pv2 & 10,1 & 1200 & 19 & 854 \\
\hline Pv3 & 7,4 & 746 & 167,9 & 548 \\
\hline Média & 8,0 & 879,6 & 146,3 & 547,5 \\
\hline
\end{tabular}

Fonte: Elaborado pelo autor (2016).

Tabela 4 - Tabela com os principais cátions e ânions em mg/l.

\begin{tabular}{|c|c|c|c|c|c|c|c|c|c|c|}
\hline Poço & $\mathrm{Ca}^{+2}$ & $\mathbf{M g}^{+2}$ & $\mathrm{Na}^{+}$ & $\mathbf{K}^{+}$ & $\mathrm{Fe}^{2+}$ & $\mathrm{Cl}^{-}$ & $\mathrm{SO}_{4}^{-2}$ & $\mathrm{HCO}_{3}{ }^{-}$ & $\mathrm{CO}_{3}{ }^{-2}$ & $\mathrm{NO}_{3}^{-}$ \\
\hline Pv1 & 50,60 & 15,02 & 47,2 & 18,20 & 0,00 & 50,80 & 84,10 & 352,23 & 1,03 & 0,00 \\
\hline Pv2 & 6,40 & 0,73 & 102,58 & 224,25 & traço & 145,00 & 1,92 & 12,14 & 7,05 & Traço \\
\hline Pv3 & 28,70 & 23,4 & 101,9 & 25,00 & 4,71 & 110,00 & 41,20 & 256,50 & 0,30 & Traço \\
\hline Média & 28,57 & 13,05 & 83,89 & 89,15 & - & 101,93 & 42,41 & 213,82 & 6,37 & Traço \\
\hline
\end{tabular}

Fonte: Elaborado pelo autor (2016) e complementados pela fórmula de Logan (1965).

A média dos valores calculados de cálcio $\left(\mathrm{Ca}^{+2}\right)$ nos três poços foi de $28,57 \mathrm{mg} / 1$, esse resultado está dentro da faixa de ocorrência (10 e $100 \mathrm{mg} / \mathrm{l})$ das águas subterrâneas.

$\mathrm{O}$ magnésio $\left(\mathrm{Mg}^{+2}\right)$ está dentro limite natural de águas doces que é 1-100 mg/1. E juntamente com o cálcio $\left(\mathrm{Ca}^{+2}\right)$ contribuíram para dureza da água subterrânea no Pv3, visto que ambos os elementos apresentam propriedades similares e são os principais responsáveis por este fenômeno nas águas.

O sódio $\left(\mathrm{Na}^{+}\right)$é o principal elemento que ocasiona aumento constante da salinidade em águas naturais do ponto de vista catiônico. O Pv2 e Pv3 tiveram teores acima do natural para águas subterrâneas $(0,1-100 \mathrm{mg} / \mathrm{l})$. Tanto o Pv1 como o Pv3 captam águas do cristalino (rocha), onde há presença de feldspatos (plagioclásios), minerais fontes de $\mathrm{Na}^{+}$.

Frequentemente as concentrações de potássio $\left(\mathrm{K}^{+}\right)$nas águas subterrâneas é quase ausente com teores inferiores a $10 \mathrm{mg} / \mathrm{l}$. Porém concentrações anômalas de 224,25 mg/1 
foram detectadas no Pv2. Esse alto teor de potássio pode ser devido a captação da água na camada aquífera freática superior onde nesse trecho o $\mathrm{K}^{+}$pode ser bem mais móvel devido a lixiviação de materiais contaminantes consequentes da percolação e infiltração da água da chuva.

O ferro na forma de hidróxido ferroso $\left(\mathrm{Fe}^{2+}\right)$ característico de um ambiente redutor tem o teor bem expressivo no Pv3, ultrapassando o limite de potabilidade que é $0,3 \mathrm{mg} / 1$ (Portaria $N^{\circ} 2914 / 2011$ ), o alto valor pode estar relacionado com a presença de minerais ricos em ferro, por exemplo, a hematita, magnetita, goethita e biotita, no eluvião captado.

No Pv2 concentração do cloreto $\left(\mathrm{Cl}^{-}\right)$está acima da média em relação aos demais poços o que evidencia que essa água em tempos pretéritos pode ter tido contribuições de águas de fonte marinha.

Quanto ao sulfato $\left(\mathrm{SO}_{4}{ }^{-2}\right)$ os teores ficaram em média de 50,4 mg/l, frequentemente as águas subterrâneas apresentam teores inferiores a $100 \mathrm{mg} / \mathrm{L}$. No Pv2 o SO $4^{-2}$ foi quase ausente, ele pode ter sido reduzido pela matéria orgânica oriunda das argilas orgânicas sobreposta à camada aquífera freática superior.

Os dados foram complementados nos três poços em relação aos ânions $\mathrm{HCO}_{3}{ }^{-} \mathrm{e}_{3}{ }^{-}$

2 com os cálculos utilizados pela fórmula de Logan (1965). As águas subterrâneas no Pv2 têm o $\mathrm{pH}>8$, só nessa condição o carbonato $\left(\mathrm{CO}_{3}^{-2}\right)$ está mais presente nas águas subterrâneas.

A principal espécie química que indica alguma alteração na qualidade da água por origem antrópica é o nitrato $\left(\mathrm{NO}_{3}{ }^{-}\right)$. Concentrações elevadas de nitrato na água subterrânea denotam a ocorrência de contaminação advinda de águas servidas (proveniente do esgoto), principalmente em ambiente urbano. Contudo, os resultados analíticos das análises de nitrato foram ausentes a traços (pequenas concentrações).

\section{Classificação hidroquímica das águas}

De acordo com o Diagrama de Piper as águas subterrâneas nos três poços foram classificadas em bicarbonatadas no Pv1 e Pv3, e cloretadas no Pv2.

No Pv2 por seu nível de explotação ser mais raso deverá também refletir a composição química de águas da chuva, mais recente e bicarbonatada, porém o alto teor de cloretos pode estar relacionado a uma liberação de sais oriundos da camada de argila orgânica 
sobreposta à camada do Aquífero freático. Corroborando com os dados hidroquímicos já mencionados neste poço que evidencia contribuições de águas marinhas, mas também continentais, em tempos passados, visto que foram encontrados conchas de lamelibrânquios ser vivente do ambiente flúvio-marinho.

Segundo Hem (1985), as águas subterrâneas, nas áreas próximas à zona de recarga tem um caráter bicarbonatado decorrente do sistema $\mathrm{CO}_{2}-\mathrm{H}_{2} \mathrm{O}$ estabelecido. A evolução hidrogeoquímica, localmente, das águas do Aquífero Boa Viagem reflete as condições do clima tropical chuvoso, na qual predomina um solo eluvial resultante de intenso intemperismo.

Figura 05: Diagrama Triangular de Piper mostrando a classificação hidroquímica das águas no Pv1, Pv2 e Pv3.

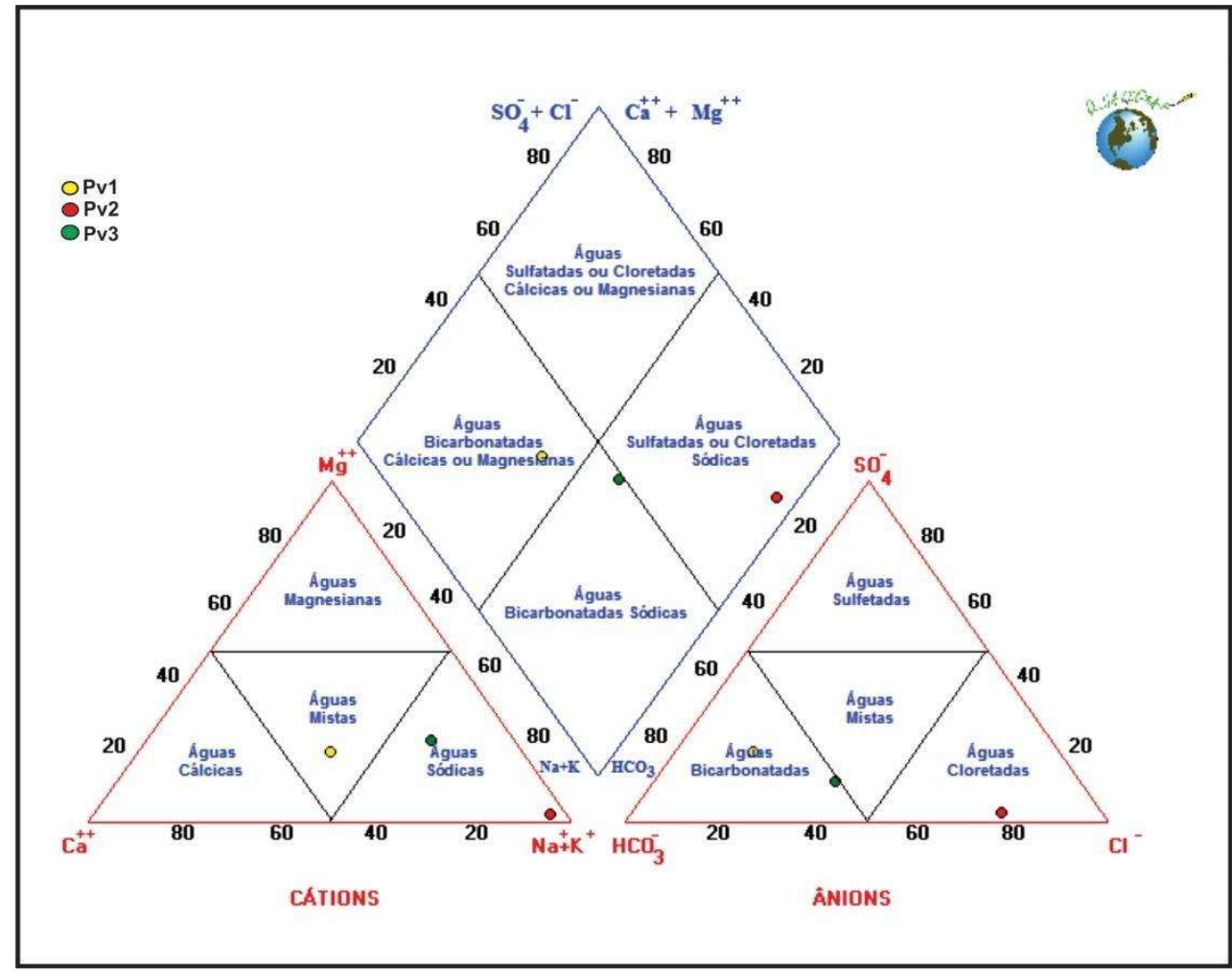

Fonte: Elaborado pelo autor (2016).

\section{CONSIDERAÇÕES FINAIS}

O modelo hidrogeológico respondeu aos objetivos iniciais, pois introduz, aprofunda e consolida novos conhecimentos do aquífero Boa Viagem, fundamental para a gestão dos 
recursos hídricos no município de Recife. O estado de Pernambuco apesar de possuir uma das melhores legislação de águas subterrâneas do Brasil, não apresenta uma legislação adequada sobres os recursos hídrico subterrâneos rasos e freáticos, não tendo nenhum controle sobre esses sistemas aquíferos e suas obras de captação. O presente trabalho é fundamental para que os órgãos gestores dos recursos hídricos elaborem uma legislação especifica sobre a exploração de água subterrânea. Destaca-se ainda que existem, poucos estudos enfocando o aquífero Boa Viagem, principalmente no bairro da Várzea, aquífero de comportamento diversificado e muito vulnerável à contaminação por fontes potenciais de contaminação (fossas sanitárias residenciais, efluentes domésticos e industriais, vazamentos da rede de esgoto sanitário, cemitérios, vazamentos de combustíveis em postos de combustíveis, dentre outros), em função de suas características de aquífero superficial pouco profundo, sedimentos diversos (cascalhos, areias, siltes e argilas de texturas variadas), e das suas dimensões espaciais, resulta numa grande variação dos parâmetros hidrodinâmicos e dos perfil litológicos. Destaca-se ainda que o principal usuário desse sistema aquífero Boa Viagem é à população de baixa renda, pelo baixo custo das obras de captação, somado também, as irregularidades do abastecimento de águas na região.

\section{REFERÊNCIAS}

APAC. Disponível em <http://www.apac.pe.gov.br $>$

Atlas do desenvolvimento humano na Região Metropolitana do Recife, 2011-nova tiragem.

Disponível em <http://www.recife.pe.gov.br $>$ Acessado em 10 de nov., 2017.

Batista, R.P. Estudo Hidrogeológico da Planície do Recife. 1984. 91p. Dissertação de Mestrado, UFPE, Recife, 1984.

Barbosa J. A. Evolução da Bacia Paraíba durante o Maastrichtiano-Paleoceno Formações Gramame e Maria Farinha, NE do Brasil. 2004. 219 p. Dissertação de mestrado, UFPE, Recife, 2004.

Bittencourt, A.C.P. et al. Quaternary marine Formation of the state of Bahia (Brazil). In: Suguio, K; Fairchild, R.I; Martin, L; Flexor, J.M. (eds) - Proceedings of the "1978 International Symposium on Coastal Evolution in the Quaternary". São Paulo (SP), 1979. p. 232-253.

BRASIL, Ministério da Saúde. Portaria n. ${ }^{\circ}$ 2.914, de 12 de dezembro de 2011. Dispõe sobre normas de potabilidade de água para o consumo humano. Brasília: SVS, 2011. 
Costa, W. D., Santos, A.C., Costa Filho, W.D. A gestão dos Aquíferos costeiros de Pernambuco. In: Anais do XIII Congresso Brasileiro de Águas Subterrâneas. 2004. Recife, ABAS. 13 p.

Custódio, E. \& Llamas, M. R. Hidrología Subterránea. 2. ed. Barcelona: Omega, 1983. 2v. Hem, J. D. Study and interpretation of the chemical characteristics of natural water. 3 ed. U.S. Geological Survey. Walter Supply Paper, (S.I) n. 2254, 1985.

HIRATA, R. et al; Team Coqueiral. Multi-layered water resources, management, and uses under the impacts of global changes in a southern coastal metropolis: When will it be already too late? Crossed analysis in Recife, NE Brazil. Science of The Total Environment, v. 618, p. 645-657, MAR 15 2018. Citações Web of Science: 1.

IBGE. Censo de 2010. Disponível em: <http://www.ibge.gov.br/home/ estatistica/populacao/censo2010/default.shtm>. Acessado em 15 de jul., 2015.

KOPPEN, W. Climatologia. México: Fundo de Cultura Econômica, 1948. 253p.

Logan, J. - The Interpretation of Chemical Analyses of Water. USAID, 1965.

Rand, H. M. \& Mabesoone, J. M. 1982. Northeastern Brazil and the final separation of South America and Africa. Paleogeography Paleoclimatology, Paleoecology, 38: 163$183 \mathrm{p}$.

SANTOS, A. C., 2008. Noções de Hidroquímica. In: Feitosa, F. A. C. \& Manuel Filho, J., 2008. Hidrogeologia: Conceitos e Aplicações. CPRM, LABHID-UFPE. Cap. 5. P. 325 357. 